\title{
Koncepti odzivanja na nasilje med ničelno toleranco in restorativnostjo
}

Robi Kroflič

$\mathrm{N}$

asilje kot oblika proaktivne agresivnosti, za katero je značilno namerno uveljavljanje nesorazmerja moči med nasilnežem in žrtvijo (Olweus, 1995: II-I2), velja za obliko ravnanja, ki ga za nedopustno označujejo vse etične teorije oziroma moralni nauki. Zato se tudi v pedagoškem kontekstu pojavlja označevanje nasilja kot nedopustne oblike vedenja ne glede na pedagoško teorijo ali kulturni kontekst. Geslo »ničelna toleranca do nasilja se torej kaže kot splošno sprejeta norma oziroma kot humanistična osnova politike ničelne tolerance. Shouse (2005: 312) zapiše, da ničelna toleranca »postane izraz humanističnih idealov $s$ tem, da je razumljena kot sredstvo za zaščito članov šolske skupnosti pred resnimi zdravstvenimi in varnostnimi grožnjami”. Kako se odzvati na nasilno vedenje, da bi preprečili njegovo nadaljnje pojavljanje, in kaj storiti, da se nasilje sploh ne bi pojavilo v vzgojnem okolju, pa ostaja predmet številnih razprav.

\section{Kaj nam sporoča politika ničelne tolerance do nasilja?}

Če sem geslo »ničelna tolerance do nasilja« opredelil kot splošno sprejeto etično normo ne glede na teoretski in kulturni kontekst, znotraj politike ničelne tolerance naslavlja simbolno oziroma ekspresivno vlogo kaznovanja $s$ tem, da »posreduje pomembna družbena sporočila in zagotavlja močan občutek družbene kohezivnosti in kolektivnega zavedanja (prav tam: 3II). Enostavno povedano: politika, ki vsako vrsto nasilja označi za

Članek Koncepti odzivanja na nasilje med ničelno toleranco in restorativnostjo je nastal v okviru raziskovalnega programa št. $P_{5}-0174$ Pedagoško-andragoške raziskave - Učenje in izobraževanje za kakovostno življenje v skupnosti, ki ga financira Javna agencija za raziskovalno dejavnost Republike Slovenije. 
nedopustno in vredno resne kazenske obravnave, s tem izkazuje svojo kolektivno pripravljenost za obrambo norm nenasilja, ki so tudi zdravorazumsko sprejete kot obče veljavne. Zato ni naključje, da bomo v družbenih sredinah, ki so vsaj načelno zavezane spoštovanju temeljnih človekovih pravic, naleteli na obrambo tega gesla kot popolnoma nevprašljivega. $O$ tem na primer priča razprava, ki sta jo sprožili Komisija Državnega sveta za državno ureditev in Komisija Državnega sveta za kulturo, znanost, šolstvo in šport ob obravnavi letnega poročila varuha človekovih pravic Republike Slovenije za leto 2007, v kateri so se državni svetniki »zavzeli /.../ za krepitev spoštovanja, moralne in etične avtoritete Varuha človekovih pravic in soglašali v prizadevanju do ničelne tolerance do nasilja « (Za ničelno toleranco do nasilja, 2008).

A teoretska analiza politike ničelne tolerance do nasilja, ki se je $\mathrm{v}$ ZDA začela pojavljati v sedemdesetih letih dvajsetega stoletja, dokončno pa se je uveljavila v devetdesetih letih in postopno prodirala tudi v Evropo (glej Kodelja, 20ı0; Kroflič, 2008; Sardoč in Prebilič, 2015; Wacquant, 2008), pokaže precej drugačno sliko. $Z$ vidika kriminoloških in penoloških teorij politika in prakse ničelne tolerance predstavljajo »kolaž / teoretsko nezdružljivih, op. R. K./ pristopov k družbenemu nadzoru. Opišemo jih lahko kot ,retributivne $v$ smislu, da kazen predstavlja , pravično povračilo‘ (just desert) - moralno logično posledico nemoralnega ali kriminalnega dejanja; kot ,utilitarne $\mathrm{v}$ smislu, da je namen kaznovanja zmanjšanje pojavov kršitev družbenih norm; in kot , rehabilitacijske $v$ smislu, da se bodo študenti, ki niso bili dokončno izključeni iz šole, vanjo vrnili bolj previdni in ubogljivi. Poleg tega ničelna toleranca ponuja doseganje teh ciljev na učinkovit (ali ,birokratski') in pravno urejen (ali ,legalistični') način.« (Shouse, 2005: 312)

Da so opisane dimenzije ničelne tolerance konceptualno nezdružljive, opozarjajo številni domači in tuji avtorji (glej na primer Kodelja, 2010; Sarodoč in Prebilič, 2015; Shouse, 2005; Skiba, 2010 idr.). Najprej velja omeniti načelno kritiko »netolerance do nasilja « kot humanističnega ideala. Ker je vsaka kazen zavestno prizadejanje bolečine, ničelna toleranca pa je oblika netolerance, morata biti posebej občutljivo in natančno etično utemeljeni. Do vzpostavitve upravičene meje tolerance (do netolerantnega) ter pravične kazni pa etične teorije ne ponujajo enoznačnih odgovorov (Kodelja, 20ı).

Mnogo bolj izdelano je teoretsko stališče do nezdružljivosti kazni kot pravičnega povračila $\mathrm{v}$ kontekstu retributivne teorije in $\gg$ načrtne arbitrarnosti« kaznovanja $\mathrm{v}$ utilitarizmu, še posebej tako imenovane »teorije razbitih oken« (Sardoč in Prebilič, 20I5). Slednja se je uveljavila kot vizija policijske prakse, ki se od preganjanja kriminala preusmeri 
v vzdrževanje reda, dostojnega vedenja in skrbi za okolje, ki večinskemu prebivalstvu vliva občutek varnosti (Wilson in Kelling, 1982). Wilson in Kelling sta utemeljitev svoje vizije našla v socialno-psihološkem eksperimentu Zimbarda iz poznih šestdesetih let, ki je dokazoval, da se kriminal v neurejenem okolju (»razbita okna«) pojavi hitreje kot v urejenem okolju: zapuščen avto bodo lokalni prebivalci hitreje izropali v neurejenem kot $\mathrm{v}$ urejenem okolju, avto $\mathrm{z}$ razbitim steklom pa bo hitro izropan tudi v urejenem okolju (prav tam). Če torej »eno razbito okno «, ki v besedilu Wilsona in Kellinga simbolizira postopače, brezdomce, prostitutke, pa tudi glasne mladostnike in $\mathrm{z}$ grafiti porisane zgradbe, vodi $\mathrm{k}$ spodbujanju resnejših kriminalnih odklonov, bi z zaščito »moralnega reda« po meri dostojnega prebivalstva, torej z doslednim preprečevanjem in strogim sankcioniranjem nedostojnega vedênja, lahko preprečili razraščanje kriminala (prav tam).

Opisano policijsko strategijo je v devetdesetih letih dvajsetega stoletja uveljavil Guiliani v elitnem predelu Manhattna v New Yorku, po sprejetju odloka o preprečevanju vnosa orožja in nevarnih predmetov v šole pa se je začela širiti po ameriških šolah v obliki strogega nadzora in nesorazmernega kaznovanja manjših prekrškov z namenom, da se preprečijo hujše oblike nasilja (Skiba, 2000). Utilitarna logika preprečevanja možnega nasilja je prevladala nad strogim in doslednim, a vendar sorazmernim retributivnim sankcioniranjem prekrškov. Geslo »trije udarci in si izključen« (three strikes and you are out) (Giroux, 2009) je privedlo da množičnega izključevanja učencev in dijakov latino- ter afroameriškega porekla na podlagi nepravičnih disciplinskih praks, nezdružljivih z (re)distributivno teorijo pravičnosti (prav tam; Skiba, 2000). Čeprav sta že Wilson in Kelling (1982) svarila pred nevarnostmi zlorabe policijskih pooblastil, ko se njihovo delo od odzivanja na kriminalno vedênje preusmeri v zaščito moralnega reda, so analize praks ničelne tolerance tako v lokalnih politikah kot pri vodenju šol pokazale, da prevlada utilitarnih kaznovalnih načel vodi $k$ neupravičenim pritiskom na moteče posameznike, ki jih družba, zasnovana na kulturi strahu (Giroux, 2009; Newburn in Jones, 2007) in spektakelskosti odločnega kaznovanja (Manning, 2007), zlahka tolerira po zdravorazumskem načelu manjšega zla.

Razširjenost politike strogega odzivanja na vsakršno kršitev družbenih pravil se je v kriminologiji in penologiji sedemdesetih let uveljavila na podlagi še ene sporne teoretske predpostavke, to je na kritiki permisivne tretmajske politike »kaznovanja «, zlom katere naj bi zaznamoval upor kaznjencev v zloglasnem zaporu Attica (Petrovec, 1998), in to kljub temu, da je šlo za enega od zaporov $\mathrm{z}$ najbolj represivno, torej $\gg$ netretmajsko« obravnavo najhujših zločincev. Ker je v istem času postala močno 
popularna tudi kritika permisivne, »otrokocentrične« vzgoje (Jeznik, Kroflič in Štirn-Janota, 2017), torej ni naključje, da se je podoben trend disciplinskih postopkov začel uveljavljati tudi v pedagogiki.

Teoretska kritika utilitaristično utemeljene tretmajske politike prevzgoje je poleg neučinkovitosti permisivne prevzgoje izpostavila še tezo, da je retributivna teorija kaznovanja $\mathrm{z}$ načeloma neizpodbitno dokazane kršitve zakona ter sorazmernosti resnosti kaznivega dejanja in višine sankcije izpostavila edino načelno etično utemeljitev kaznovanja, medtem ko utilitarizem s pozornostjo, usmerjeno v koristnost učinka sankcije, zlahka zagovarja etično neupravičeno »eksemplarno《 kaznovanje, če le-to obeta zaželene učinke, to je zmanjšanje števila prekrškov (Kodelja, 20ıо). A vsaj od vzpostavitve restorativne pravičnosti v sedemdesetih letih dvajsetega stoletja in postopnega uvajanja restorativnih praks $\mathrm{v}$ pravosodni in šolski sistem teoretska kontroverza med retribucijo in utiliratizmom, ter med avtoritativnim in permisivnim disciplinskim pristopom $\mathrm{v}$ pedagogi$\mathrm{ki}$, dobi tekmeca $\mathrm{v}$ konsistentno oblikovani restorativni teoriji legitimiranja sankcij in naboru vzgojnih ter disciplinskih praks (mediacije, restitucije itn.), s katerimi lahko pomembno dopolnimo dosedanje prevladujoče metode preprečevanje nasilja. Gre za sankcioniranje prekrškov in šolske svetovalne dejavnosti.

Glavne razloge za vzpon in širjenje politike ničelne tolerance $\mathrm{v}$ zahodnem svetu pa kritični teoretiki pripisujejo politično-ekonomskim in kulturnim spremembam v ZDA in Evropi. Na prvem mestu je zagotovo vzpon »biopolitike neoliberalizma « (Giroux, 2009) in konservativnih politik s kultom osebne odgovornosti in privatizacijo družbenih problemov. Če so zagovorniki tretmajskih pristopov izpostavljali številne osebne in družbene determinante, ki ljudi silijo v odklonsko vedenje, $s$ terapevtskimi in družbenimi spremembami pa lahko zajezimo okoliščine, ki posameznika ali marginalizirano skupino spodbujajo $\mathrm{k}$ nasilnim dejanjem, neoliberalizem zanika kakršnokoli odgovornost družbe in »naredi bolj družbeno sprejemljivo prelaganje krivde za njihove probleme na revne, brezdomce, nezavarovane, brezposelne in druge prikrajšane posameznike in skupine ter hkrati poveže državo prostega trga s kaznovalnim režimom«. (Prav tam: str. 2-3)

Drugi kulturni fenomen, ki podpira nesorazmerno avtoritarno kaznovanje vsakršnega odklonskega vedênja, je sistematično ustvarjanje kulture strahu (Giroux, 2009; Newburn in Jones, 2007) in posledično splošne sprejemljivosti spektakla odločnega kaznovanja (Manning, 2007), ki sem ga izpostavil že ob teoriji razbitih oken. Newburn in Jones (2007: str. 235) tako zapišeta, da na primer Guiliani ob uvajanju politike ničelne tolerance na Manhattnu sicer ni razumel, kako izboljšati kakovost življenja, je 
pa »ujel val. Razumel je frustracije, ki izhajajo iz strahu pred kriminalom.« Manning (2007: str. 327) pa dodaja, da je spektakel »scena, ki jo moramo gledati, čutiti in slaviti, namesto da bi jo razumeli ... Ta estetska politika ustvari moralno igro, kasneje orkestrirano z županom Guilianijem, v kateri sta dobro in zlo jasno razločena, zlu nasprotujemo, se z njim soočamo in ga preganjamo, ,dobro pa zmaguje.« Ko so torej mediji po streljanju v šoli Columbine in dodatno po napadu ir. septembra na Svetovni trgovinski center napihnili zgodbe ogroženosti, se je strah pred nasiljem le še stopnjeval, hkrati z njim pa je šlo lažje sprejemanje ekscesnega nadzora in kaznovanja tudi za ceno zmanjševanja temeljnih človekovih pravic in utišanja zahteve po legitimiranju kaznovalnih politik.

Giroux pa ob teh skrbno načrtovanih kulturnih spremembah izpostavi še eno, ki se neposredno dotika šolske politike: »Po streljanjih v srednji šoli Columbine in Virginia Tech so otroci večinoma opredeljeni skozi svet pobesnelih medijskih spektaklov, ki jih poganjajo senzacionalistične pripovedi in panika zaradi ogrožajočih mladostnikov. Namesto, da bi bili prikazani kot žrtve ,krize moškosti in moškega besa, kulture nenadzorovanega dostopa do orožja in medijev, ki projektirajo normativne podobe nasilne moškosti in iz morilcev ustvarjajo zvezdnike (Montgomery in Chester, 2009), so mladostniki predstavljeni kot psihološko vznemirjeni, potencialno brezobzirni morilci (zlasti mladi vojni veterani), skupinski posiljevalci (lažno obdolženi igralci lacrossa na Univerzi Duke), šolski strelci in desenzibilizirani domači teroristi.« (Giroux, 2009: str. 9I) Obče prisotno »podobo ranljivega otroka (Dahlberg, Moss in Pence, 2007), ki ga lahko ustrezno vzgojimo samo ob strokovni podpori (Furedi, 200I), torej $\mathrm{v}$ devetdesetih letih dvajsetega stoletja začne izpodrivati podoba $\gg$ nevarnega mladostnika - potencialnega terorista $\ll$, katerega divje narave nismo dovolj zgodaj ukrotili s strogo disciplino, ki temelji na grožnji z izključevanjem (»trije udarci in si izključen «). Zgoraj prikazane izpeljave v celoti podpira tudi leta 2007 objavljena študija Philipa Zimbarda Luciferjev efekt. Razumeti, kako se dobri ljudje spremenijo $v$ slabe, ki je nekakšna metaanaliza preteklih socialnopsiholoških eksperimentov (Milgrama, Ascha, Zimbarda itn.) in sodobnih represivnih praks (zapora v Guantanamu). V njej avtor izpostavi tri povezane dejavnike, ki vplivajo na človekovo vedenje: dispozicijskega (»slabo jabolko «), situacijskega (»sod smodnika«, bad barrel) in sistemske strukture moči (ustvarjalci soda smodnika, barrel-makers). Zaščitniki sistema običajno radi pripišejo vso krivdo dispozicijskim lastnostim prestopnikov, in to ne samo v penoloških institucijah, ampak tudi šolah (Morrison, 2014: str. I24). Takšna težnja k označevanju potencialnih nasilnežev kot slabih jabolk (ali strokovno rečeno: mladostnikov s čustvenimi in vedenjskimi motnjami) je 
seveda $\mathrm{v}$ jedru nezdružljiva $\mathrm{z}$ mednarodno sprejeto normo inkluzivnega izobraževanja in njeno osnovno idejo, da moramo v inkluzivnih okoljih najprej poskrbeti za odstranjevanje sistemskih ovir, ki ranljivim posameznikom onemogočajo uspešno vključevanje $\mathrm{v}$ družbeno sredino. Izkušnja neprilagojenega okolja, kjer posameznik ne more uresničiti svojih zmožnosti, pa pogosto povzroči čustvene težave, slednje pa lahko vodijo tudi $\mathrm{k}$ nasilnemu vedenju.

\section{Od politike ničelne tolerance $\mathrm{k}$ teoriji restorativnosti}

Trditev, da je retribucija edina teorija pravičnega kaznovanja, primerna tudi za sankcioniranje prekrškov v šoli (Javornik, 200I), je od uveljavitve načela restorativnosti nesprejemljiva; res pa odraža spoznanje, da se je redistributivna teorija pravičnosti kot temeljna uveljavila $\mathrm{v}$ zahodnih individualističnih kulturah, restorativna teorija pravičnosti pa v kolektivističnih kulturah (Maorov v Novi Zelandiji, številnih afriških ljudstev, Navajo Indijancev v Severni Ameriki, Iunitov v Kanadi ...) (Selman, Cremin in MyCluskey, 2014).

In vendar spoznanje o vrednosti restorativnih vzgojnih in disciplinskih politik prodira tudi $\mathrm{v}$ zahodni svet. Eden najbolj sistematičnih in kritičnih raziskovalcev učinkov politik ničelne tolerance $\mathrm{v}$ ZDA, Russel Skiba, je $s$ sodelavci v povzetku poročila za Ameriško združenje psihologov zapisal, da alternativo ničelni toleranci, ki je poslabšala šolsko klimo, povečala stopnje neprimernega vedenja, osipnikov in celo sodnih kazenskih obravnav, ki kot cevovod vodijo od šole proti zaporu, lahko nudijo tudi restorativni pristopi, strogi retributivni ukrepi pa naj bodo uporabljeni samo v najtežjih primerih, a še takrat moramo pozornost usmeriti $\mathrm{k}$ potrebam vseh vključenih, tudi storilcev (Skiba et al., 2008). Še bolj pomenljivo je oblikovanje Priročnika o programih restorativne pravičnosti, ki ga je oblikovala Agencija Združenih narodov za droge in kriminal, v katerem je med drugim zapisano, da so restorativni programi pravičnosti utemeljeni na prepričanju, da morajo biti vse stranke v sporu vključene $\mathrm{v}$ reševanje konflikta in iskanje pravičnega povračila nastalih škodljivih posledic dejanj. Ti programi naj bi »spodbujali miroljubno reševanje konfliktov, promovirali strpnost in inkluzivnost, gradili spoštovanje do različnosti in promovirali odgovorne skupnostne prakse « (Handbook on Restorative Justice Programmes, 2006: str. 5). Nenazadnje velja omeniti, da se v Priporočilih o načinih oblikovanja in uresničevanja vzgojnega načrta osnovne šole (2008), ki jih je sprejelo Ministrstvo za šolstvo in šport, v poglavju o svetovanju in sporazumnem reševanju medsebojnih problemov in sporov pojavljata dva najbolj razširjena restorativna postopka - mediacija in restitucija. Oba ukrepa pogosto najdemo v vzgojnih načrtih osnovnih 
šol kot obliki tako imenovanih alternativnih vzgojnih ukrepov, ki jih lahko uporabimo ob disciplinskih prekrških namesto formalnega vzgojnega opomina (čeprav se v naših šolah ustrezno vpeljan sistem mediacije, še posebej vrstniške, zelo redko izvaja).

Čeprav so bile restorativne metode mediacije in restitucije oblikovane kot »kurativni pristopi « ob nastalih konfliktih in prekrških, se je v šolski praksi razvila tudi ideja celovitih restorativnih šolskih pristopov, ki vključujejo tudi preventivne vzgojne dejavnosti, kot so na primer mirovni krogi in skupnostne konference (Sia, 2014), temeljijo pa na dogovornem oblikovanju vrednot in odnosnih veščin (Blood in Thorsborne, 2005) in seveda na oblikovanju strpne in inkluzivne kulture ter klime medosebnih odnosov.

Temeljne značilnosti restorativnih pristopov Van Ness (2014: str. 33) opredeli s koncepti soočenja (storilca in žrtve), poprave (škode) in transformacije (konfliktnih pogledov, ki postanejo bolj odnosno naravnani, ter odnosov samih), številni avtorji pa jih opredeljujejo še z geslom, da restorativni pristopi reševanje konfliktov vračajo $v$ skupnost in omogočajo reintegracijo udeležencev konflikta v šolsko skupnost (npr. Cowie, 20I 4: str. 75).

V uvodu v zbornik Restorativni pristopi h konfliktom v šlah Sellman, Cremin in McCluskey (20I4: str. I-2) opišejo naslednje pozitivne učinke restorativnih pristopov: spodbujajo pozitivno vedenje in odnose, so alternativa kaznovalni politiki ničelne tolerance, zagotavljajo bolj inkluzivno in harmonično šolsko kulturo, imajo lahko pozitiven vpliv na učence, ki so prvič soočeni s posledicami lastnih dejanj, preprečujejo vrstniško nasilje, žrtev pa je postavljena v središče procesa. Cowie (2014: str. 79-80) temu dodaja še opis psiholoških učinkov restorativnih ukrepov v šolah: izboljša se šolska klima, poveča se razumevanje pomena pravil in zaupanje $v$ načine njihovega uveljavljanja med mladimi, odnosi med mladimi in odraslimi so bolj pozitivni, poveča se zaupanje v prosocialno delovanje in obrambo ranljivih vrstnikov, izboljša se razumevanje vzrokov, zakaj storilci posegajo po nasilnem vedenju, raziskuje se empatija ob čustveni pretresenosti (distresu) bližnje osebe in izboljša se razumevanje dejavnikov konfliktov in nasilja.

$\mathrm{V}$ opisih pozitivnih in negativnih vidikov restorativnih pristopov pa naletimo na odprto vprašanje, ali lahko restorativnost razumemo kot novo teorijo, celo paradigmo pravičnosti, ali pa gre zgolj za gibanje zagovornikov novih metod za reševanje (in preprečevanje) konfliktov. Završnik (2008) se nagiba k oceni, da lahko govorimo o restorativnosti kot novi paradigmi pravičnosti, ki se $\mathrm{v}$ temelju razlikuje od filozofskih predpostavk modernega prava in je z njimi v jedru nezdružljiva, kar pa ne pomeni, da 
ni mogoče tudi pri sodnih sporih uveljavljati posamezne restorativne metode kot dopolnitve klasičnih sodnih obravnav, utemeljenih na konceptu retributivne pravičnosti.

Ključni razliki med restorativnostjo in dvema prevladujočima konceptoma kaznovanja, retributivnim in utilitarističnim, sta v pojmovanju človeka in družbe. Antropološka osnova modernih pogledov na kaznovanje sta kartezijanski subjekt, ki razumno presoja o koristi (utilitarizem) oziroma smislu in pravičnosti (retributivizem) kaznovanja (prav tam: str. 132), in družbena pogodba, na kateri temelji moderna država in jo ščitimo $s$ preganjanjem kriminala in kaznovanjem kršitev zakona, da bi s tem ponovno uveljavili (»zacelili«) moralno tkivo družbe, ki je bilo s kaznivim dejanjem pretrgano (prav tam: str. I29).

Teorija restorativnosti pa se navezuje na postmoderni subjekt, ki se oblikuje bolj tekoče, njegova racionalnost pa ni univerzalna, ampak je povezana z zgodovinskimi, institucionalnimi, sociološkimi in kulturnimi pogoji življenja: »Subjekt je vedno (pre)oblikovan, aktivno in pasivno, preko razmerij moči z drugimi in preko razmerja do samega sebe ... Tovrstno pojmovanje je izjemno podobno implicitnemu restorativističnemu pojmovanju subjektivnosti: $\mathrm{v}$ postopku je mogoče $s$ komunikacijo in pritegnitvijo skupnosti preoblikovati obsojenčevo in žrtvino identiteto in samopripoved /angl. rebiographing)/.«(Prav tam: str. 132) Če se to preoblikovanje dogaja v zaporu, bo kaznovana oseba sicer razvila subjektivnost, ki ji omogoča znajdenje $\mathrm{v}$ tej sredini, ne pa tudi strategij uspešnega vključevanja $\mathrm{v}$ družbo, kar je eden temeljnih razlogov povratništva (prav tam: str. 133).

Ravno tu naj bi imeli restorativni pristopi odločilno prednost pred klasičnim kaznovanjem: »Postopki restorativne pravičnosti z drugačnim prerazporejanjem moči spreminjajo posameznikovo razmerje do kulturnih, družbenih in institucionalnih oblik moči, ki ga sooblikujejo ... Storilca vzpodbuja(jo), da najde pomen in se preoblikuje v kontekstu skupnosti.«(Prav tam) Zato naj bi imeli restorativni postopki vsaj teoretično večji potencial spreminjanja storilca od retributivih ukrepov, in to ne le v kontekstu penoloških institucij, ampak tudi vrtcev in šol.

Problem, na katerega opozarja Završnik, pa je spremenjen koncept družbe in njenega simbolnega reda kot »abstraktnega tretjega (prav tam: str. 130). Čeprav zagovorniki restorativne pravičnosti izpostavljajo pomen teh ukrepov za oblikovanje inkluzivne skupnosti, je po mnenju Završnika njihovo pojmovanje skupnosti predmoderno. Predmodernost pa nima le romantične podobe pristnih, osebno vpletenih odnosov, ampak tudi hrbtno plat: »Pričakovana občutja posameznikov so bila občutja pobožnosti, pietete in spoštovanja tradicije. Subjekt naj bi vedno ravnal 
tako, 'kot je prav', 'pravilno', pričakovano, za razliko od modernega pričakovanja po samoiniciativnem, kreativnem, 'učinkovitem' in 'uspešnem' vedenju, ki se ne ozira na (domnevno) 'organsko' povezanost posameznika in lokalne skupnosti.« (Prav tam: str. 132) Takemu mnenju se ob praktičnih poskusih obujanja tradicionalnih skupnostnih konceptov, kot je na primer afriški ubuntu, pridružuje Lephalala (2014), ki zapiše, da se »zaradi represivnega apartheida $v$ južnoafriških šolah pojavlja nasilje in fizično kaznovanje, ki ga želijo zamenjati s praksami na podlagi koncepta ubuntu. A tudi ta koncept še vedno vključuje nekatere tradicionalne diskriminatorne prakse (starost, spol, socialni položaji), pretirani kolektivizem in konformizem, čemur se mladi upirajo. Ubuntu bi morali kritično osvetliti in na njem zgraditi restorativne prakse.« (Prav tam: str. 54-55)

Iz druge perspektive očitke o predmoderni subjektivnosti in preveliki potopljenosti posameznika v skupnost obravnava tudi Cremin (20I4: str. IIO-III), ki opozarja na možnost ponovne viktimizacije žrtev, če jih silimo v soočenje $s$ storilci, možno netransparentnost disciplinskih postopkov in pretirano spodbujanje osebne odgovornosti storilca (responsibilization), ki jo lahko razumemo kot novo obliko governmentalnosti (governmentality). Premisleka vredno pa je tudi opozorilo Van Nessa (2014: str. 36) o tem, kaj se zgodi, če restorativne metode uvedemo v okolja, kjer prevladuje klasični retributivni pogled na obravnavo kriminala: zahteva po popravi bo postala kaznovalna, restorativna soočenja pa bodo postala sredstva vzbujanja sramu in stigmatizacije, ne reintegracije.

V zagovor restorativnim ukrepom je treba v zvezi s konceptom družbenega izpostaviti, da se restorativne metode, kot so na primer restorativne konference in mirovni krogi, ukvarjajo $\mathrm{z}$ vprašanji vzpostavljanja simbolnega reda šole na načelih demokracije, inkluzivnosti in kulture nenasilja. Res pa je, da take razprave ne temeljijo na nevprašljivem simbolnem redu statusnih pravil, ki jih postavi vodstvo šole, ampak jih podvržejo pogajanjem med sošolci in učitelji na osnovi temeljnih moralnih vrednot. Tudi Završnik v zaključku razprave Konceptualne zagate restorativne pravičnosti - nova paradigma modernega odzivanja na kriminaliteto? izpostavi, da »ideje restorativne pravičnosti $\mathrm{v}$ absolutni meri ne morejo nikoli popolnoma vstopiti v moderno (kazensko) pravo «, kar pa »seveda $\mathrm{v}$ ničemer ne zmanjšuje etične vrednosti restorativne pravičnosti« (Završnik, 2008: str. I38). Zato bi bilo hipotetično mogoče zaključiti, da je uvajanje restorativnih metod $\mathrm{v}$ šole problematično, ko branimo legalistično zasnovo vzgojnega delovanja, ko pa koncept vzgojnega delovanja naslonimo na etične osnove, ta strukturna zadrega $v$ veliki meri odpade. Seveda moramo tudi v tem primeru ohraniti klasično pravno zaščito 
in iz nje izhajajoče upravno-administrativne disciplinske ukrepe kot orodje za zaščito žrtev nasilja, ki ga uporabimo, ko drugi vzgojni in disciplinski ukrepi niso uspešni.

Razprave o restorativnih šolskih pristopih pogosto spremlja tudi očitek o teoretskih pomanjkljivostih, vezanih na nedodelan koncept (postmodernega) subjekta in njegove subjektivnosti. Tako Mac Allister (2014) opozarja, da lahko osnovno idejo restorativnosti, to je obnovo odnosa med storilcem in žrtvijo, razumemo napačno v Platonovem smislu, da imamo ljudje nekaka naravna »pozitivna čustva «, ki bi jih lahko z vzgojo obnovili. Bolj je prepričljiva razlaga, da mora socialna in emocionalna vzgoja vključiti učence, da se učijo prek različnih bolečih ali prijetnih občutij, vključujoč tudi prosocialne emocije, kot je na primer (reintegracijski) sram (glej tudi Cremin, 2014) oziroma empatična krivda, ki jo po Hoffmanu (2000) občuti storilec, ko zazna prizadetost žrtve zaradi lastnega dejanja. Da se take prosocialne zmožnosti pojavijo $\mathrm{v}$ otroku že zelo zgodaj, pričajo tako empirične (npr. Kroflič in Smrtnik-Vitulić, 2015; Turiel, 2004) kot teoretske raziskave (npr. Klein, 1997; Kristjansson, 2004), z vzgojo pa jih lahko krepimo, če vzamemo konfliktne situacije kot optimalno učno orodje.

Zadnja kritika restorativnih načinov reševanja konfliktov, ki jo želim izpostaviti, je povezana s prepričanjem neoklasicistov (sodobnih zagovornikov retribucije in doslednega sankcioniranja prekrškov), da je $\mathrm{v}$ primeru nespoštovanja pravil edino pričakovanje resne sankcije tisto, ki nagovarja potencialnega storilca kot $\gg$ odgovorno osebo $\ll, s$ tem pa se krepi odgovornost za posledice lastnega ravnanja (načelo specialne pervencije). Past, ki se povezuje z utilitarnimi tretmajskimi pristopi, ki ob nudenju terapevtske svetovalne pomoči nagovarjajo storilca kot $\gg z ̌ r t e v 《$ številnih determinant, ki se jim ne more upreti brez naše pomoči, zagotovo ne velja za mediacijo in restitucijo. $V$ obeh primerih je izpostavljena odgovornost storilca glede na retributivne pristope celo potencirana. Ne le, da restorativisti storilca jemljejo kot subjekt in ga s tem štejejo za odgovornega za posledice vedenja, od njega celo pričakujejo, da se je zmožen soočiti s posledicami lastnega ravnanja (torej s prizadetostjo žrtve) in poiskati način, kako se pred žrtvijo in skupnostjo odkupi za svoje neprimerno vedenje (Kroflič, 20rI). Prej kot prikrito permisivnost bi zagovornikom restorativnosti lahko očitali pretiran pritisk na storilca, ki naj bi z žrtvijo dosegel poravnavo/spravo kot novo obliko skupnostnih pritiskov oziroma governmentalnosti (Cremin, 2014). Ali kot zapiše Završnik (2008: str. 135), takšno dojemanje poravnave »posameznika popolnoma 'utopi' v družbenem. Posameznik je dojet kot izključno ali pretežno v funkciji države ali skupnosti in se mora zato praviloma podrediti tej celoti ne le na zunanji, 
manifestativni ravni, temveč na številnih osebnih ravneh (npr. moralni, običajni, religiozni, politični). Sprava tam tako dobiva ne le pravno pozunanjeni značaj, temveč že kar moralno religiozne dimenzije ...«

\section{Vzgoja in discipliniranje kot način spopadanja $s$ »trpinčenjem na daljavo «}

Vidne oblike nasilja so v sodobnih družbah hitro prepoznane kot nedopustne oblike vedênja. To vsekakor ne velja za manj vidne oblike nasilja (socialno izključevanje) in nasilje na daljavo (spletno nasilje), kjer stik med storilcem in žrtvijo ni neposreden. V močno tekmovalno naravnanih (neoliberalnih) okoljih, kjer je spopad za boljši družbeni položaj ena temeljnih norm družbenega napredka, družbeno obrobje pa je razumljeno kot posledica manj sposobnih posameznikov, ki so si za slabe pogoje krivi sami, občutljivost za trpljenje, povezano s socialnim obrobjem oziroma izolacijo, zelo težko prepoznamo. Hkrati nas individualizacija življenja vodi $\mathrm{k}$ manjšanju občutljivosti za trpljenje drugega, posledično pa celo k splošni družbeni anomiji (Durkheim, 2013; Merton, 1938).

Če je razsvetljenska, deontološko zasnovana etika delovala prepričljivo v vrednotno bolj homogenih družbah osemnajstega in devetnajstega stoletja, se v atomiziranih okoljih postmoderne pokaže, kako zlahka je mogoče doseči razcep med etično zavestjo in spoštljivim odnosom do sočloveka, ki naj bi bil po Baumanu eden ključnih razlogov za uspeh Hitlerjevega projekta holokavsta. V svoji študiji Moderna in holokavst je namreč pokazal,

da nacističnih zločinov zoper Žide niso zagrešili 'človeški monstrumi', ampak običajni ljudje, ki v času izvajanja holokavsta niso spreminjali lastnih osebnih vrednot in etičnih standardov, saj so v zasebnem življenju ostajali ljubeči možje, žene, starši in zvesti prijatelji. Da bi načrtovalci holokavsta omogočili takšno ravnanje, ki je zahtevalo razcep med etično zavestjo in spoštljivimi medčloveškimi odnosi do konkretnih pripadnikov židovskega rodu, so morali najprej preprečiti sobivanje Nemcev in Židov. Med kristalno nočjo, ko so odredi SS dobili ukaz, da z nasilnimi dejanji napadejo Žide po večjih nemških mestih, večina nemškega prebivalstva ni odobravala tega dejanja, zato je Hitler preklical nadaljnje načrtovane akcije, najgorečnejše pripadnike odreda SS pa celo kaznoval. Ko pa je začel načrtovati nacionalno zakonodajo, ki je Žide obravnavala kot abstraktno kategorijo, konkretne Žide preselil v gete in jih z dehumanizacijskimi pristopi v koncentracijskih taboriščih razčlovečil, je nemško prebivalstvo v strašljivem številu pristalo na podporo Hitlerjevi politiki holokavsta. (Kroflič, 2007: str. 63) 
Kar danes pomembno zmanjšuje občutljivost za psihično, socialno in spletno nasilje, je zagotovo $v$ konkretne medčloveške odnose nevpleteni subjekt, ki na drugega $v$ etičnem odnosu gleda kot na lasten alter ego, torej kot na bitje, ki si zasluži naše spoštovanje zgolj takrat, ko je nosilec iste racionalnosti in avtonomije kot mi sami. Ko torej človeku preprečimo osebno vpletene odnose z drugim, njegovo trpljenje (ali pa sreča) v nas ne prebudi več odgovornosti za spoštljiv in skrben odnos (prav tam: str. 64). Če $\mathrm{k}$ temu dodamo še situacijske in sistemske dejavnike (pri Zimbardu »sod smodnika « in »sistemske strukture moči«), ki jih v primeru vrstniškega nasilja predstavljajo tihi opazovalci, vrstniki in odrasli, se nespoštljiva komunikacija, pri nas praktično nikoli javno označena in sankcionirana kot sovražni govor, pogosto prevesi v druge oblike nasilja.

Ob takih predpostavkah mehanizma poostrenega družbenega nadzora in »ločevanja gnilih jabolk« ne delujeta prepričljivo. Morrison (2014: str. 129) predlaga, da kaznovanje »gnilih jabolk« nadomestimo $s$ širjenjem povezovalne kulture pripadnosti in blagostanja, poudarek na strahu, napakah in retributivnih sankcijah preusmerimo k izpostavljanju velikodušnosti, izobilja in sočutja, odgovornost do zakonov in avtoritete zamenjamo z odgovornostjo do družbe brez strahu, poudarek na močnih institucijah pa preusmerimo k močnim skupnostim.

Da lahko politiko ničelne tolerance uspešno nadomestimo z vzgojnimi dejavniki, katerih osrednji cilj je krepitev občutljivosti in sočutja do drugega, kar tvori jedro restorativnih in induktivnih vzgojnih praks, potrjuje kar nekaj raziskav. Tako Cremin (20Ir: str. 168) v evalvaciji, opravljeni na petnajstih šolah v Veliki Britaniji, ki so uvedle vrstniško mediacijo, ugotavlja, da je glavna prednost tega pristopa kot dela celovitega vzgojnega koncepta pomen $\gg$ moralnega vzdušja in vrednot, ob katerih se učenci počutijo močnejše«, ter dodaja, da »je mediacijski proces najbolj dovzeten za najtežje zaznane, posredne in psihološke oblike konfliktov in vrstniškega nadlegovanja (bullyinga). Zanimivo je, da so tovrstne oblike konfliktov in vrstniškega nadlegovanja povezane z jezikom, iz česar je mogoče sklepati, da učenci, ki se poslužujejo mediacije, razumejo, da je z besedami mogoče škodovati drugim, a je jezik hkrati sredstvo, ki prinaša rešitev.« (Prav tam: str. 173) Prav tako raziskava učinkov uvajanja celovitega induktivnega pristopa v treh oddelkih javnega vrtca (Kroflič in Smrtnik Vitulić, 20I5) dokazuje, da so po petmesečnem uvajanju otroci dosegli boljše rezultate na lestvici socialnih kompetenc od kontrolne skupine, hkrati pa se niso uresničili strahovi, da indukcija s pritiskom na občutenje empatične krivde ob nedopustnem ravnanju lahko spodbudi čustvene težave s ponotranjanjem. Nasprotno, otroci v eksperimentalni skupini so po uvedbi celovitega induktivnega vzgojnega pristopa in zbujanju empatične krivde 
ob dejanjih, ki so prizadela vrstnike, izkazovali manj znakov depresije, anksioznosti, izolacije in odvisnega vedenja $\mathrm{v}$ interakcijah $\mathrm{z}$ vzgojiteljicami (prav tam: str. 65).

Najbolj navdihujoča zgodba o uspešni zamenjavi politike ničelne tolerance do nasilja z induktivnimi vzgojnimi dejavnostmi (o umetnosti kot delu celovitega induktivnega vzgojnega pristopa glej Kroflič, 2010) pa je izjemen uspeh osnovne šole Orchard Garden v Bostonu, ki je ob zamenjavi vodstva leta 2010 opustila obsežen sistem nadzorovanja kot preventive pred nasiljem v skladu $z$ odlokom o šolah brez orožja, sredstva pa preusmerila $\mathrm{v}$ zaposlitev mentorjev vzgojnih aktivnosti s pomočjo umetnosti (likovnega izražanja, plesa, gledališča in glasbe). Šola je po teh spremembah izrazito izboljšala šolsko klimo, povezanost z lokalno skupnostjo in počutje otrok v šoli (obisk šole je nad 95 odstotki, izključitve so se znižale za 85 odstotkov) ter posledično postala ena od najhitreje napredujočih šol po akademski uspešnosti v Massachusettsu (http://orchardgardensk8. org; Means, 2015; Tur, 2013). Na enaki osnovi je 2012 v ZDA nastala iniciativa Turnarround Arts (http://turnaroundarts.kennedy-center.org/), ki si prizadeva za strateško rabo umetnosti v izobraževanju.

$\mathrm{Z}$ zamenjavo kaznovalnih pristopov, temelječih na pravni zaščiti človekovih pravic, se na teoretski ravni ukvarja tudi Medveš (2or8a), ki predlaga zamenjavo socialno-kritične in duhoslovne vzgojne paradigme z reformsko paradigmo, znotraj nje pa koncept vzgoje kot komunikacije $\mathrm{z}$ vrednotami. Po njegovem mnenju lahko zagotavlja univerzalno vrednotno podlago celostni vzgoji moralni sistem, v katerem so med seboj konstruktivno prepleteni različni etični diskurzi in vrednote (pravičnost, solidarnost in pripoznanje). Komunikacijo $\mathrm{z}$ vrednotami mora sprožiti učitelj, dogaja pa se v učenčevi zavesti. Ena najboljših metod spodbujanja komunikacije z vrednotami je tudi za Medveša mediacija, ki jo bolj kot zaradi empatične potopitve $\mathrm{v}$ položaj bližnje osebe ceni zaradi tega, ker $\mathrm{v}$ storilcu izzove etični razmislek o storjenem dejanju in možnosti poprave škode oziroma krivice, ki jo je storil. Hkrati isti avtor kritično obravnava tudi utilitaristični koncept šolskega svetovanja kot paternalistično dejavnost, ki učencu ne priznava zmožnosti za smiselno moralno presojo (Medveš 2or8b).

Ne glede na razlike $\mathrm{v}$ prikazanih konceptih spopadanja $\mathrm{z}$ nasiljem jih druži prepričanje, da je končna varovalka pred nasilnim delovanjem vzbujanje otrokovih/mladostnikovih kapacitet za prepoznavanje konfliktne situacije in njegove odgovornosti za moralno delovanje. Na tem naj bi bila zgrajena vzgoja za nenasilje za razliko od direktivnih mehanizmov družbenega nadzora in kaznovanja prekrškov. Takšna naravnanost pa se sklada z idejo restorativne pravičnosti kot načina reševanja konfliktov, ki 
namesto načelne obrambe posameznika pred pritiski skupnosti $\mathrm{v}$ duhu človekovih pravic izpostavlja dogovorno reševanje medosebnih konfliktov, da bi posameznik kljub drugačnosti svojih kulturnih preferenc lahko ostal povezan s skupnostjo.

\section{Zaključek}

Restorativni vzgojni in disciplinski pristopi se v svetu uveljavljajo kot resna alternativa politiki ničelne tolerance do nasilja. V članku sem poskušal prikazati, da ideja restorativne pravičnosti nadomešča doslej edino »veliko teorijo « pravičnega kaznovanja, na kateri sta temeljila moderno pravo in vzgojno-disciplinski režim razsvetljenske pedagogike, to je retributivno teorijo kaznovanja. Hkrati sem opisal tudi pasti te paradigmatske spremembe, saj je antropološka osnova restorativne pravičnosti nezdružljiva $z$ osnovo retributivne teorije, na kateri je utemeljena moderna pravna zaščita človekovih pravic. Skrajni robovi današnjih pristopov k preprečevanju nasilja, ki so nastali ob politiki ničelne tolerance - dosledno kaznovanje nasilja (ničelna toleranca) in zaščita skupnosti (teorija razbitih oken) -, se izkažejo za pretirano represivne in izključevalne.

Odprto teoretsko vprašanje, povezano z uvajanjem restorativnih pristopov kot osnove vzgojnega koncepta šole, je povezano s pojmovanjem skupnosti oziroma družbenega okvira šole. Pritrjujem teoretskim ugotovitvam Završnika (2008) in Lephale (2014), da predmoderno pojmovanje skupnosti, na katerem so zasnovani tradicionalni koncepti restorativne pravičnosti, v sedanjosti pomeni resno nevarnost za razraščanje klasičnih oblik nestrpnosti, vezanih na spolno diskriminacijo, etnocentrizem itn. Hkrati pritrjujem Van Nessu (2OI4), ki ugotavlja, da se v okoljih, kjer prevladuje retributivni pogled na obravnavo prekrškov, restorativna načela hitro sprevržejo v lastno nasprotje: zahteva po popravi bo postala kaznovalna, restorativna soočenja pa bodo postala sredstva vzbujanja sramu in stigmatizacije, ne pa reintegracije storilca v skupnost. Podobno v neinkluzivnih kulturah vključevalne politike zdrsnejo na raven »divje integracije «, to je nasilnega vključevanja posameznika v pogosto sovražno heterogeno okolje, ko drugačen posameznik postane tarča posmeha in napadov »večine«, saj se okolje ni pripravljeno prilagoditi njegovi drugačnosti (Lesar, 2009).

Izhod iz te dvojne zanke je v resnem premisleku o vzpostavitivi modela inkluzivne šolske skupnosti. Namesto tradicionalnega pojmovanja kulture kot tiste simbolne dimenzije, ki povezuje posameznike s sorodnimi identitetnimi politikami, iščemo model skupnosti posameznikov, ki jih ne druži nič skupnega (Biesta, 2017; Lingis, 1994), a so se zmožni in pripravljeni dogovoriti o ohranjanju individualnih posebnosti in hkrati 
spoštovanju drugačnosti (Bauman, 200I). Če namreč tradicionalni komunitarizem prek politike razbitih oken vzpostavlja nevarne oblike pritiskov na manjšinske skupine prebivalcev - tudi na subkulture mladostnikov, mora liberalni komunitarizem prek restorativnih praks uvesti tradicionalne oblike dogovarjanja med člani skupnosti na način, da jih očisti tradicionalnih vrednotnih opredelitev.

Uvajanje restorativnih pristopov pa terja tudi drugačno percepcijo vzgoje. Redistributivni model ničelne tolerance je zavezan tradicionalnemu kantovskemu pogledu na amoralnost divjega otroka in veri v avtoritativno direktivnost vzgoje, medtem ko restorativni pristop stavi na razvoj odprte narativne identitete ob soočenju svojih želja z drugim kot drugačnim, na motnjo egocentričnosti percepcije in vzgojo kot subjektifikacijo (Biesta, 2017; Ranciere, 2006) oziroma komunikacijo z vrednotami (Medveš, 20I8a). Koncept vzgoje z umetnostjo v osnovni šoli Orchard Garden v Bostonu dokazuje, da lahko alternativo izključujoče politike ničelne tolerance uspešno nadomestijo vzgojne dejavnosti, ki povečujejo občutljivost za različne oblike nasilja, seveda ob jasni opredelitvi, da sodobna šola še vedno potrebuje tudi dosledne disciplinske meje, zasnovane na retributivnih načelih modernega prava, ki pa jih s sankcijami brani šele takrat, ko široka paleta vzgojnih dejavnosti za nenasilje ni privedla do želenega rezultata.

\section{Literatura}

Bauman, Z. (200I) Community (Seeking safety in an insecure world). Cambridge: Polity Press.

Biesta, G. (2017) The Discovery of Teaching. New York in London: Routledge. Blood, P. \& Thorsborne, M. (2005) The Challenge of Cultural Change:

Embedding Restorative Practices in School. V: The Sixth International Conference on Conferencing, Circles and other Restorative Practices: "Building a Global Alliance for Restorative Practices and Family Empowerment". Sydney, Australia, March 3-5 2005. http://www.thorsborne.com.au/conference_papers/Challenge_of_Culture_Change.pdf (pridobljeno 20.1.2018).

Cowie, H. (2014) Restorative aproaches in schoos. A psychological perspective. V: Selman, E., Cremin, H. in McCluskey, G. [ur.], Restorative Approaches to Conflict in Schools: Interdisciplinary Perspectives on Whole School Approaches to Managing Relationships, str. 75-8I. London in New York: Routledge. 
Cremin, H. (2or I) Kaj je vrstniška mediacija?. V: R. Kroflič idr. [ur.], Kazen $v$ šoli? : Izbrani pristopi k sankcioniranju prestopkov in podpori prosocialnega ter moralnega ravnanja, str. 137-176 Ljubljana: CPI.

Cremin, H. (2014). Critical Perspectives on Restorative Justice/Restorative Approaches in Educational Settings. V: E. Selman, H. Cremin, in G. McCluskey [ur.], Restorative Approaches to Conflict in Schools: Interdisciplinary Perspectives on Whole School Approaches to Managing Relationships, str. III-I22. London and New York: Routledge.

Dahlberg, G., Moss, P. in Pence, A. (2007) Beyond Quality in Early Childhood Education and Care. Languages of Evaluation. London: Routledge (2. izdaja).

Durkheim, E. (2013) The Division of Labour in Society. Hampshire: Palgrave Macmillian.

Furedi, F. (200I) Paranoid Parenting. London: Allen Lane.

Giroux, H. (2009) Youth in a Suspect Society. New York: Palgrave.

Handbook on Restorative Justice Programmes. (2006) New York: United Nations. https://www.unodc.org/pdf/criminal_justice/Handbook_on_ Restorative_Justice_Programmes.pdf(pridobljeno 20.5.2019).

Hoffman. L. M. (2000) Empathy and Moral Development. Cambridge: Cambridge University Press.

Javornik, M. (200I) Oproblematiki vzgoje v kazenskem pravu: doktorska disertacija. Ljubljana: Oddelek za pedagogike filozofske fakultete v Ljubljani.

Jeznik, K., Kroflič, R. in Štirn-Janota, P. (2017) O vzgojnih pristopih med permisijo in otrokocentričnostjo. V: T. Narat in U. Boljka [ur], Generaciji navidezne svobode: otroci in starši v sodobni družbi. Ljubljana: Sophia.

Klein, M. (1997) Zavist in hvaležnost: izbrani spisi. Ljubljana: ISH Fakulteta za podiplomski humanistični študij: SH Zavod za založniško dejavnost.

Kodelja, Z. (2010) Politika ničelne tolerance, Šolsko polje XXI (5-6), str. I8I-I89.

Kristjansson, K. (2004) Empathy, Sympathy, Justice and the Child, Journal of Moral Education 33 (3), str. 291-305.

Kroflič, R. (2007) Vzgoja za odgovornost onkraj razsvetljenske paradigme (Od razvoja odgovora-zmožnosti k spoštljivemu odnosu in razvoju etične zavesti), Sodobna pedagogika 58 (posebna izdaja), str. 56-7I.

Kroflič, R. (2008) Ničta toleranca do odklonskega vedenja in inkluzivna šola, Sodobna pedagogika 59 (3), str. 64-74. 
Kroflič, R. (20I0) Umetnost kot induktivna vzgojna praksa (Vzgoja preko umetnosti v Vrtcu Vodmat). V: R. Kroflič idr. [ur], Kulturno žlahtenje najmlajših: razvoj identitete otrok v prostoru in času preko raznovrstnih umetniških dejavnosti. Ljubljana: Vrtec Vodmat.

Kroflič, R. (20II) Reagiranje v konfliktnih situacijah. V: R. Kroflič idr. [ur.], Kazen v soli?: Izbrani pristopi k sankcioniranju prestopkov in podpori prosocialnega ter moralnega ravnanja, str. 13-36. Ljubljana: CPI.

Kroflič, R. in Smrtnik Vitulić, H. (2015) The Effects of the Comprehensive Inductive Educational Approach on the Social Behaviour of Preschool Children in Kindergarten, CEPS Journal 5(I), str. 53-69.

Lephala, M. (2014) Merging past and present? Conflict Resolution in South African Township Schools. V: E. Selman, H. Cremin in G. McCluskey [ur.], Restorative Approaches to Conflict in Schools: Interdisciplinary Perspectives on Whole School Approaches to Managing Relationships, str. 5I-58. London: Routledge.

Lesar, I. (2009) Šola za vse? Ideje inkluzije v šolskih sistemih. Ljubljana: Pedagoška fakulteta.

Lingis, A. (1994) The Community of Those Who Have Nothing in Common. Bloomington: Indiana University Press.

Mac Allister, J. (2014) Restoration, transformation or education? A philosophical critique of restorative approaches in schools. V: E. Selman, H. Cremin in G. McCluskey [ur.], Restorative Approaches to Conflict in Schools: Interdisciplinary Perspectives on Whole School Approaches to Managing Relationships, str. 97-110. London: Routledge.

Manning, P.K. (2007) Theorizing Policing: The Drama and Myth of Crime Control in the NYPD. Theoretical Criminology 5(3), str. 315-344.

Means, A. J. (2015) Aesthetics and Educational Value Struggles. V: T. E. Lewis in M. J. Laverty [ur.], Art's Teachings, Teaching's Art. Philosophical, Critical and Educational Musings, str. 137-150. Cham: Springer.

Medveš, Z. (20r8a) Vzgoja med etičnim diskurzom in zdravo pametjo. Sodobna pedagogika $69=135(\mathrm{I})$, str. 44-69.

Medveš, Z. (2018b) Aktualno z letošnje konference Prispevki strok za svetovalno delo v praksi: šolsko svetovanje v spreminjanju pedagoških paradigem. Šolsko svetovalno delo: revija za svetovalne delavce v vrtcih, šolah in domovih 22(2), str. 4-19.

Merton, R. K. (1938) Social Structure and Anomie. American Sociological Review 3(5), str. 672-682. 
Morrison, B. (2014) Beyond the Bad Apple (Analytical and Theoretical Perspectives on the Development of Restorative Approaches in Schools). E. Selman, H. Cremin in G. McCluskey [ur.], Restorative Approaches to Conflict in Schools: Interdisciplinary Perspectives on Whole School Approaches to Managing Relationships, str. 123-131. London: Routledge.

Newburn, T. in Jones, T. (2007) Symbolizing crime control: Reflections on Zero Tolerance. Theoretical Criminology II(2), str. 22I-243.

Olweus, D. (1995) Trpinčenje učencev: Kaj vemo in kaj labko naredimo. Ljubljana: Zavod RS za šolstvo in šport.

Petrovec, D. (1998) Kazen brez zločina (Prispevek k ideologijam kaznovanja). Ljubljana: Studia humanitatis.

Priporočila o načinih oblikovanja in uresničevanja vzgojnega načrta osnovne šole (2008). Ljubljana: Ministrstvo za šolstvo in šport.

Ranciére, J. (2006) The Politics of Aesthetics. London: Verso.

Sardoč, M in Prebilič, V. (2015) Paradoksi ničelne tolerance. Teorija in praksa $52(I-2)$, str. $83-96$.

Selman, E. Cremin, H. in McCluskey, G. (2014) Contextualised, contested and Catalytic (A thematic introduction to the potential of reatorative approaches in schools. V: E. Selman, H. Cremin in G. McCluskey [ur.], , str. I-8. London: Routledge.

Shouse, R. C. (2005) Some Current threats to Humanistic Pupil Control. V: W. K. Hoy in C. Miskel [ur.], Educational Leadership and Reform, str. 30I-3I8. Connecticut: Information Age Publishing.

Sia, L. (2014) Restorative justice. An International perspective. V: E. Selman, H. Cremin in G. McCluskey [ur.], , str. II-22. London: Routledge.

Skiba, R. J. (2000) Zero Tolerance Zero Evidence. An Analysis of School Disciplinary Practice. Policy Research Report SRS2. Indiana Education Policy Center.

Skiba, R. J. idr. (2008) Are Zero Tolerance Policies Effective in the Schools? An Evidentiary Review and Recommendation. American Psychologist 63(9), str. 852-862.

Tur, K. (2013) Principal fires security guards to hire art teachers and transforms elementary school. http://dailynightly.nbcnews. com/news/2013/05/or/18005192-principal-fires-security-guards-to-hire-art-teachers-and-transforms-elementary-school?lite (pridobljeno I8. 5. 2019). 
Turiel, E. (2004) The Culture of Morality (Social Development, Context, and Conflict). Cambridge: Cambridge University Press.

Van Ness, D. W. (2OI4) Restorative justice as world view. V: E. Selman, H. Cremin in G. McCluskey [ur.], , str. 32-39. London: Routledge.

Wacquant, L. (2008) Zapori revščine. Ljubljana: Založba/*cf.

Wilson, J. Q. in Kelling, G. L. (1982) Broken windows (The police and neighborhood safety). https://media4.manhattan-institute.org/pdf/_atlantic_monthly-broken_windows.pdf(pridobljeno I8.5. 2019).

Za ničelno toleranco do nasilja. Sreda, I5.I0.2008. Dostopno na arhivski strani Državnega sveta Republike Slovenije. http://www.arhiv.ds-rs.si/ index6aI 4.html?q=node/74I (pridobljeno I8. 5. 2019).

Završnik, A. (2008) Konceptualne zagate restorativne pravičnosti - nova paradigma modernega odzivanja na kriminaliteto? Revija za kriminalistiko in kriminologijo 59(2), str. I25-140.

DOI: https://www.doi.org/I0.32320/1581-6044.30(I-2)9-27 